of molybdenum in respiration. There is no evidence at present to suggest an increase in anaerobic respiration in these circumstances. In the presence of nitrate, however, the respiratory mechanism appears to be modified. $Q_{\mathrm{O}_{2}}$ values (dry weight) in molybdenumdeficient leaves do not suggest a decreased oxygen uptake, and the increased respiratory quotient can therefore be due to three possibilities : (i) utilization of additional oxygen from nitrate; (ii) stimulation of anaerobic respiration; (iii) change of substrate.

The slightly greater respiratory quotient, $1 \cdot 04$, in nitrate plants than non-nitrate types, 0.99 , given molybdenum and the rapid increase in respiratory quotient after injection of molybdenum into nitratefed molybdenum-deficient plants support the suggestion $^{2}$ that nitrate reduction provides an additional source of oxygen in respiration. The decrease in $\mathrm{QO}_{2}$ after injection of molybdenum into deficient material (Fig. 2) suggests here that oxygen in nitrate actually competes with atmospheric oxygen consumption during rapid reduction (Fig. 1) as well as causing increased evolution of carbon dioxide (Fig. 2). The origin of the initially high respiratory quotient in molybdenum-deficient plants given nitrate is less obvious. It may be due to a steady reduction of nitrate present in very high concentrations ( $5-13$ per cent of dry weight) either mediated by a restricted nitrate reductase activity or through an alternative mechanism of low efficiency, or it may reflect the utilization of different substrates. It is hoped to elucidate some of these points in further studies.

This work was undertaken during the tenure of a special grant provided by the Agricultural Research Council under the Anglo-French Exchange Scheme by one of us (G.D.), for which grateful acknowledgment is made.

Laboratoire de Physiologie Végétale, Centre Nationale de Recherches Agronomique, Versailles. Agricultural Research Council

$$
\text { E. J. HewitT }
$$

Unit of Plant Nutrition (Micronutrients), Long Ashton Research Station, Bristol.

2 Hewitt, I. J., and Jones, E. W., J. Pomol., 23, 254 (1947). Mulder, E. G., Plant and Soil, 1, 94 (1948). Stout, P. R., and Meagher, W. R., Science, 108, 471 (1948).

${ }^{2}$ Arnon, D. I., Soil Sci., 44, 91 (1937).

s Ducet, G., and Rosenberg, A. J., Bull. Soc. Chim. Biol. 33, 321 (1951).

" Hewitt, E. J., "Sand and Water Culture Methods used in the Study of Plant Nutrition". Commonwealth Bureau of Horticulture, Tech. Comm. No. 22 (East Malling, 1952).

${ }^{5}$ Agarwala, S. C., and Hewitt, E. J., J. Hort. Sci. (in the press). Agarwala, S. C., Iong Ashton Res. Sta. Ann. Rep., p. 70, 1951.

\section{Brownish-yellow Discoloration of Salt Cod and Halophile Calcium-needing Micro-organisms}

IN recent years the salt cod industry of Iceland has suffered heavy losses by the deterioration of the product caused by brownish-yellow discoloration. The deterioration sets in 10-20 days after salting, the flesh of the fish first becoming creamed and yellow and turning brownish-yellow to brown in three to five weeks. Such a deterioration has been observed in other countries, such as Canada and Great Britain.

Dyer ${ }^{1}$ considered the staining to be caused by small amounts of iron in the fishery salts, and in the report of the Food Investigation Board for 1951 it is suggested that the browning may be of the Maillard type'. I have studied the phenomenon for the past four months and have come to the conclusion that the deterioration is caused by halophile calcium-needing micro-organisms. This conclusion was drawn from the following results.

In commercial samples of salt cod, the calcium content of the skin and bone-free deteriorated fish was found to be 0.28 per cent, that of the unspoiled fish $0 \cdot 16$ per cent (eight samples). The content of calcium in excess of sulphate was 0.20 per cent in the spoiled fish and 0.08 per cent in the unspoiled.

The content of calcium of the salt in the experimental stacks was reduced and the content of sulphate also, only much more. Thus the ratio calcium to sulphate for one sample of contaminated salt increased from 0.46 to 1.38 in forty-three days in the stack. For another stack with an excess of salt, the same ratio increased from 0.37 to 0.46 in seventeen days and to 0.54 in thirty-six days.

Sterilizing the salt by heating for $4 \frac{1}{2} \mathrm{hr}$. at 150 $180^{\circ} \mathrm{C}$. stopped the discoloration caused by the salts, as shown by salting experiments. Three samples were tested. Discoloration was increased by adding calcium chloride to the contaminated salts. No increase was noted by adding magnesium sulphate.

In one of the samples of fishery salts, there was 0.04 per cent calcium chloride, 0.02 in the second and none in the third.

One of the samples with a calcium content of 0.05 per cent caused discoloration when calcium chloride was added, but not otherwise.

It is concluded that the micro-organisms reduce the sulphate in calcium sulphate to obtain the calcium in a soluble form.

A detailed report of this work will be published elsewhere.

Chemical Laboratory,

PálL Olafsson

Icelandic State Herring-oil and Meal Factories, Siglufjördur, Iceland.

1 Dyer, W. J., "Yellow Stains in Salt Fish" Fish. Res. Bd. Canada,
Progress Reports of the Atlantic Coast Stations, No. 45 (1949). Progress Reports of the Atlantic Coast Stations, No. 45 (1949).

${ }^{2}$ Rep. Food Invest. Bd. for 1951 (Dept. Sci. and Indust. Res., London,

\section{Paper Chromatographic Examination of the Alkaloid Extract in Toxicology}

RECENT advances in chemotherapy present the police toxicologist with the problem of extracting and identifying from viscera an increasing number of basic organic compounds. In the past, methods of identifying less than milligram quantities of basic poisons extracted from the body have depended on colour reactions and micro-crystallography. Little is known of the fate of these new drugs in the body, and their reactions with the alkaloidal reagents are often unpublished. Paper chromatography is obviously the method of choice for the preliminary sorting on a microgram scale of these poisons from one another and from their metabolites.

We wish to report a solvent system which we have found to be most useful in separating compounds that may be found in this basic extract. The method of revealing the spots has been that of Munier and Machebceuf ${ }^{1}$. It has been found that the use of this modified Dragendorff reagent provides an additional criterion to the $R_{F}$ value because it produces with different compounds a variety of shades of orange and red. $20 \mu \mathrm{gm}$. of a substance is easily detected. 